\title{
MISSION APPLICABILITY ASSESSMENT OF INTEGRATED POWER COMPONENTS AND SYSTEMS
}

\author{
R.P. Raffaelle, ${ }^{1}$ A.F. Hepp, ${ }^{2}$ G.A. Landis, ${ }^{2}$ and D.J. Hoffman ${ }^{2}$ \\ 1) Rochester Institute of Technology, Rochester, NY 14623 \\ 2) NASA Glenn Research Center, Cleveland, $\mathrm{OH} 44135$
}

\begin{abstract}
The need for smaller lightweight autonomous power systems has recently increased with the increasing focus on micro- and nanosatellites. Small area high-efficiency thin film batteries and solar cells are an attractive choice for such applications. The NASA Glenn Research Center, Johns Hopkins Applied Physics Laboratory, Lithium Power Technologies, MicroSat Systems, and others, have been working on the development of autonomous monolithic packages combining these elements or what are called integrated power supplies (IPS). These supplies can be combined with individual satellite components and are capable of providing continuous power even under intermittent illumination associated with a spinning or Earth orbiting satellite. This paper discusses the space mission applicability, benefits, and current development efforts associated with integrated power supply components and systems. The characteristics and several mission concepts for an IPS that combines thin-film photovoltaic power generation with thin-film lithium ion energy storage are described. Based on this preliminary assessment, it is concluded that the most likely and beneficial application of an IPS will be for small "nanosatellites" or in specialized applications serving as a decentralized or as a distributed power source or uninterruptible power supply.
\end{abstract}

\section{INTRODUCTION}

The development of small satellites has generated a need for smaller lightweight power systems. ${ }^{1}$ These systems will most likely combine some devices for power generation and some for storage. The combination of high specific power solar cells and rechargeable thin film batteries is one attractive possibility for missions that receive intermittent solar illumination such as a small satellite in low-earth orbit (LEO). The integration of these two elements together with associated power management components is referred to as an integrated power supply (IPS).

The physical characteristics of an IPS can differ dramatically, and to a large extent will be governed by the specific application. Regardless of the configuration, every IPS will include devices for power generation, energy storage and power conditioning. Researchers at the Johns Hopkins Applied Physics Lab have designed and built an IPS that combines an array of high efficiency crystalline solar cells with high specific energy lithium batteries. In contrast, the IPS that were designed by Microsat Systems (ITN Energy Systems) combined thin film CuInGaSe cells with thin film solid state rechargeable lithium batteries. Lithium Power Technologies have also developed a thin film IPS by combining a-Si thin film PV arrays with thin film polymer rechargeable lithium batteries. So far, the IPS systems created at NASA Glenn have used a variety of PV arrays. ${ }^{2}$ We have tested IPS that utilized thin film $\mathrm{CuInGaSe}$ and $\alpha-\mathrm{Si}$ arrays as well as GaAs monolithically interconnected modules (MIM). The energy storage devices have 
been various types of both lithium and lithium ion batteries (i.e., solid state, polymer, coin cells, thin film cells). The common feature of the devices developed at GRC thus far is that they have been designed to meet the needs of microelectronic devices in space. Most IPS systems have focused on the use of photovoltaic (PV) power generation and Li-ion battery energy storage. However, one can easily envision the use of other energy generation sources (e.g., alpha or beta voltaics, micro fuel cells, etc.) and other storage devices (e.g., super-capacitors, MEM flywheels, etc.) based upon energy needs and mission requirements.

Many of the IPS systems developed to date and those planned for the future include thin-film photovoltaic (TFPV) power generation. TFPV has been under development for some time. TFPV sample cells and panels have flown in space, but a full TFPV solar array has not yet been built. The principle benefits of TFPV arrays include very high mass specific power (W/kg), radiation tolerance and good stow-ability. The mission benefits of TFPV solar arrays have been identified, and may soon be realized once full-scale TFPV arrays are constructed and space qualified. $^{3}$

In comparison to TFPV power generation, thin-film energy storage (TFES) is a relatively recent development. Very small thin-film lithium-ion batteries have been developed and tested in the lab for use in multi-chip modules (MCMs). ${ }^{4}$ With a typical operating range between $3.0 \mathrm{~V}$ and $4.2 \mathrm{~V}$, the useable capacity of these initial TFES batteries is very small, ranging from 0.2 to $10 \mathrm{mAh} / \mathrm{cm}^{2}$. However, specific energies as high as $200 \mathrm{Whr} . \mathrm{kg}$ have already been achieved with batteries that are capable of cycling 60,000 times.

Because of the similarity in the materials and processes that go into TFPV and TFES devices, it is practical to consider combination of the two. It is feasible to combine a TFPV cell on a Kapton $^{\mathrm{TM}}$ substrate with a Li-ion thin-film battery sandwiched in Kapton ${ }^{\mathrm{TM}}$. With the further addition of very small power conditioning and control electronics, an Integrated Power Source (IPS) is possible.

An IPS is unique in that it combines three formerly separate functions of an electrical power system into an integrated package. Taking advantage of this feature, and it applying it locally, so to speak, results in a decentralized or distributed power bus. The use of a local IPS could allow distant portions of a satellite or space probe to be operated without a physical wire to provide power. Wiring can be $10 \%$ of the mass of a spacecraft in some cases. Removal of the physical wires would considerably simplify design. The command and control could use infrared or microwave remote control (similar to "wireless internet" control). Potential applications include:

- Actuators for deformable mirrors for large (15-25 meter) space telescopes

- Interferometric sensors

- Wireless remote actuators for spacecraft attitude control

- Gossamer spacecraft controls

- GPS attitude sensors

- Dipole array antenna element

A decentralized power bus concept applied to discrete components, leads to the notion of an IPS as an uninterruptible power source, or UPS, to increase the reliability of essential spacecraft functions. Two specific functions that could benefit from this are computer memory and spacecraft communications.

CMOS ("volatile") memory is faster than non-volatile memory and has higher density and lower mass. However, if power is not maintained on the memory, it is erased. The amount of 
power required for this is extremely small, and a tiny IPS could be incorporated to make certain that even in a low-power condition, the memory remains charged.

Loss of attitude control on many satellites is a fatal error. This can occur when solar arrays lose pointing and batteries discharge. When battery voltage drops so low that the spacecraft central processing unit (CPU) and radio receiver lose power, there is no way to regain control of the satellite. An IPS could be used as a back-up power system, designed to provide enough power to run a low bit-rate omni-directional receiver and the spacecraft CPU only when the main power system failed.

\section{IPS CHARACTERISTICS/DESCRIPTION}

The physical characteristics of an IPS can differ dramatically, and to a large extent will be governed by the specific application. Regardless of the configuration, every IPS will include devices for power generation, energy storage and power conditioning. So far, TFES and IPS systems created at NASA Glenn have been developed to meet the needs of microelectronic devices in space.

The power requirements placed on an IPS will play a large role in determining the ultimate size of the device. The voltage of the PV portion of the device is determined by the nature of the p-n junction, or, in other words, the materials used. In the case of a GaAs homo-junction device this will be around $1.0 \mathrm{~V}$. For thin-film a-Si or CuInSe $\mathrm{C}_{2}$ (CIS) PV, the voltage generated will be somewhat less $(0.4-0.8 \mathrm{~V}){ }^{5}$ However, through the use of monolithically interconnected modules (MIM), many junctions can be put together in series to increase the voltage. Unfortunately, the available current will always be a function of the active surface area of the device. The current density presently available from a thin-film CIS cell is rather small due to its low photovoltaic conversion efficiency, although the goal of NASA Glenn's in-house TFPV program is $>20 \%$ efficiency via a dual junction thin-film PV cell like the one illustrated in figure 4.

The voltage of a Li-ion battery is based on its chemistry and is primarily determined by the material used in its cathode. A vanadium pentoxide or manganese oxide battery will have and open circuit voltage of $3.0 \mathrm{~V}$, whereas a nickel cobalt cell will be $4.2 \mathrm{~V}^{6}$

In a way similar to PV cells, Li battery cells can be connected in series configurations to produce different voltages. However, the amount of energy that can be stored in a cell, its capacity, is determined primarily by its volume. Thus for a thin-film Li-ion battery, the capacity will be determined in the same way the current capability of the PV cell is determined - by the area of the device. The size also impacts the rate at which a battery can be charged and discharged (i.e., the smaller the battery the smaller the charging and discharging currents it can handle).

Ideally, in order to minimize the control electronics associated with an IPS, the photovoltaic array is designed such that its output voltage matches the voltage needs of the battery and its current output is sufficient to charge the battery while simultaneously providing power to the load. The precise sizing of the array and battery will also be dependent on the anticipated illumination scheme. For example, in a typical 90-minute low-earth orbit (LEO) period, the battery will have to support the electrical load for 35 minutes of eclipse. During the 55 minute insolation (daylight) period, the solar array has to provide load power while fully re-charging the battery. ${ }^{4}$

The matching of the solar array and batteries for these small power systems is essential as the parasitic power loss in a conventional charge controller normally used in a larger power system actually exceeds the output of a small IPS. Once the PV and battery are matched, the only 
additional components required are a blocking diode to prevent the battery from discharging through the PV array during eclipse.

The Li-ion batteries play a large role in determining the temperature regime in which these systems are suitable. Li-ion cells will deliver a sizeable fraction (i.e. $80 \%$ ) of their capacity at temperatures as low as $-20{ }^{\circ} \mathrm{C}{ }^{7}$ Below such a temperature they do not perform well. However, they do not exhibit permanent damage if they are cycled between larger temperatures regimes (i.e., plus or minus $80^{\circ} \mathrm{C}$ ). ${ }^{8}$ The high temperature performance is much less of an issue with thin-film Li-ion batteries as they have been shown to operate well at temperatures up to $60{ }^{\circ} \mathrm{C} .{ }^{9}$ Thermal control issues associated with IPS applications are discussed later.

\section{POTENTIAL BENEFITS}

As one might anticipate, the primary benefit resulting from the combination of two extremely light weight devices providing distinct functions is a less complex, reduced volume, light weight system providing an integrated function. A thin-film IPS could serve as the main power system on a spacecraft or satellite. Scaling up the manufacturing methods should allow an IPS to deliver the highest specific power and energy for the lowest cost. Reducing power system mass, which is typically $20 \%$ to $30 \%$ spacecraft dry mass, will help reduce launch mass, perhaps enough to enable a mission concept previously too heavy to fly, or allow the use of a smaller, cheaper launch vehicle. Incorporating energy storage with power generation reduces volume formerly required by traditionally separately located chemical batteries, freeing up valuable space for other systems or an increased payload.

The main benefit of using an IPS as a distributed power system is a reduction in spacecraft complexity, especially with respect to power distribution wiring, simplifying spacecraft integration. In this instance, numerous IPSs are used to provide continuous power to loads, either spacecraft bus components or payload instruments, in situ, wherever the component is located. Of course this does require components to be located such that they have view of the sun for at least some portion of the orbit. The use of IPSs as power sources for MCM sensors that may be placed wherever they are needed in a "postage stamp" fashion could have tremendous benefit in future nanosatellite design.

\section{STARSHINE 3}

The first in-space demonstration of an IPS, although with a GaAs monolithically integrated module (MIM) solar cell and a Li-ion thick "coin" battery, should occur on launch of the Starshine-3 satellite in late summer $2001 .^{10}$

Figure 1. Starshine 3.

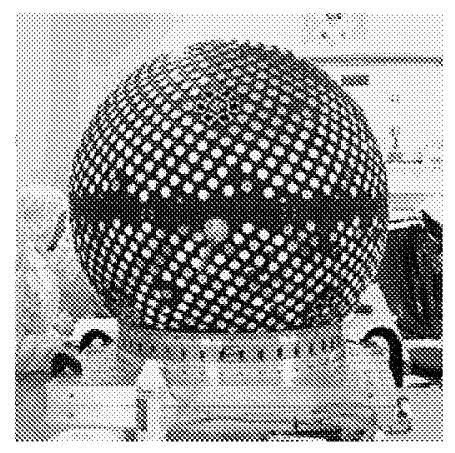


The Starshine 3 satellite is $1.0 \mathrm{~m}$ in diameter and has a mass of $88 \mathrm{~kg}$. Its surface is covered with 1500 student polished mirrors, 31 laser retroreflectors, $48-2 \mathrm{~cm} \times 2 \mathrm{~cm}$ triple junction solar cells manufactured by Emcore, and our 5 integrated power supplies. It is scheduled for launch on a Lockheed Martin Athena I rocket from Kodiak Alaska on September 29, 2001. It will be deployed by a Lightband system at a $67^{\circ}$ inclination with a fixed rotational velocity of $5^{\circ}$ per second in a low earth orbit (LEO) with a period of 92 minutes. The data will be downloaded using a transmitter operating at a frequency of $145.825 \mathrm{MHz} .{ }^{11,12}$

The IPS we have developed combines a 7 junction $-1 \mathrm{~cm}^{2}$ monolithically interconnected GaAs module (MIM) (see Figures 2 and 3) with a lithium ion battery. Ideally, the output of the high-voltage small area MIM would be designed to match the open circuit voltage of the lithium ion battery. ${ }^{2}$ The MIM we used in this case has more than enough voltage and current to both charge a Li ion battery with a $\mathrm{CoO}_{2}$-based cathode (e.g., $\left.\mathrm{V}_{\mathrm{oc}}=4.2 \mathrm{~V}\right)^{6}$ and power an equivalent load.

The load for this demonstration is a small temperature sensor. These sensors are strategically placed about the spacecraft to monitor the temperatures of the critical components (e.g., batteries, solar cells, electronic boards), both inside and outside of the satellite.

Three prototype IPS were developed. The first incorporated a commercial Panasonic ML2020 rechargeable manganese dioxide Li ion battery (see Figure 2a). ${ }^{7}$ This $3.0 \mathrm{~V}$ "coin cell" had a diameter of $2.0 \mathrm{~cm}$, thickness of $2.0 \mathrm{~mm}$, mass of $2.2 \mathrm{~g}$, and a nominal capacity of 45.0 mAh.

(a)

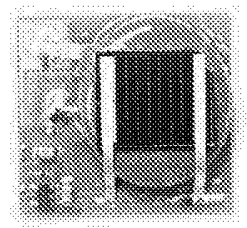

Figure 2. a) Starshine 3 IPS prototype with Panasonic battery; b) IPS with Litestar battery on mounting stub.

The second was a solid state thin film Litestar battery developed by Infinite Power Solutions (see Figure $2 \mathrm{~b}$ ). ${ }^{13}$ This $4.2 \mathrm{~V}$ had a $\mathrm{LiNi}_{\mathrm{x}} \mathrm{Co}_{1-\mathrm{x}} \mathrm{O}_{2}$ cathode, a LiPON electrolyte, and Li metal anode. It had an active area of $2.69 \mathrm{~cm}^{2}$, capacity of $800 \mu \mathrm{Ah}$, and approximate mass of $1.23 \mathrm{~g}$, including its substrate, contacts and sealants. The third battery was a $4 \mathrm{~cm}^{2}$ and $1.38 \mathrm{~g}$ thin film polymer battery developed at the NASA Glenn Research Center. The electrolyte for this $4.2 \mathrm{~V}$ battery consisted of lithium (bis) trifluoromethane-sulfonimide, ethylene and propylene carbonate, and the polymer polyacrylonitrile (PAN). The cathode was this same polymer impregnated with $\mathrm{LiNi}_{0.8} \mathrm{Co}_{0.2} \mathrm{O}_{2}$. The anode was also the same polymer impregnated with graphite.

The IV photoresponse of the MIM was measured at the Glenn Research Center using a simulated air mass zero (AM0) spectrum. The array had a short circuit current of $3.16 \mathrm{~mA}$, an open circuit voltage of $6.93 \mathrm{~V}$, an $80 \%$ fill factor, and an efficiency of $12.18 \%$ (see Figure 3 ). 


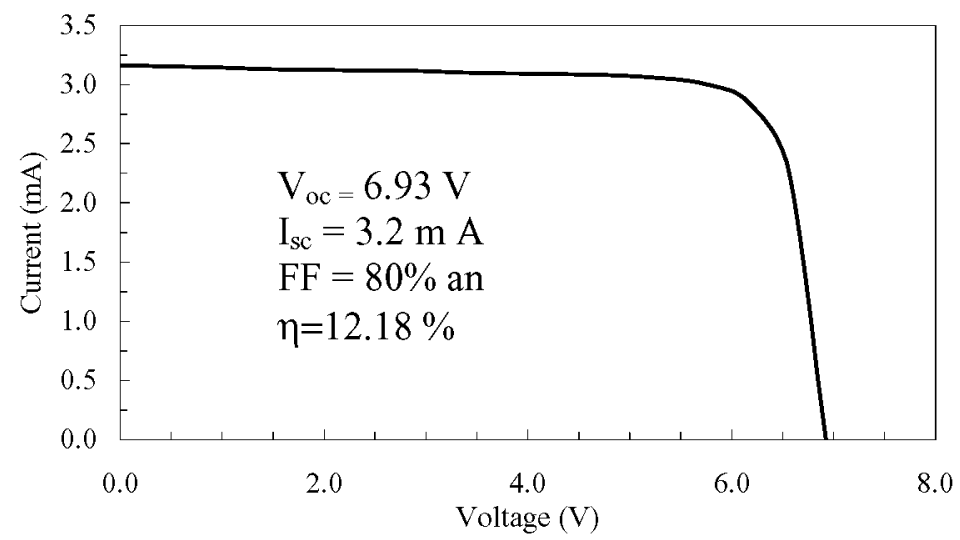

Figure 3. AM0 photoresponse of the GaAs MIM.

The capacity of the various batteries used in the IPS were measured. A typical charge/discharge curve for the Glenn polymer battery is shown in Figure 4. The coin cell has the largest capacity but is also the largest and most massive. Conversely the Litestar has less capacity but is substantially lighter and thinner. It has the highest specific power at $200 \mathrm{Wh} / \mathrm{kg}$.

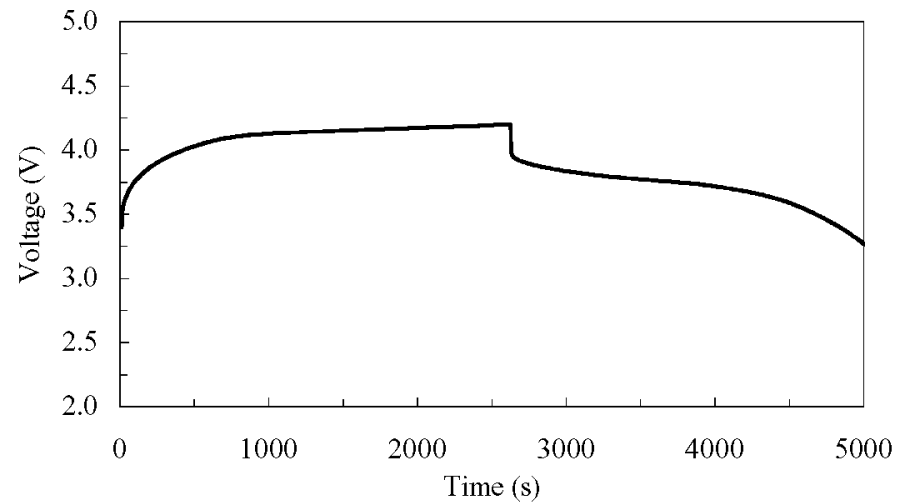

Figure 4. Charge/discharge behavior of $4.2 \mathrm{~V}$ lithium polymer battery with a $100 \mu \mathrm{A}$ discharge rate.

The prototype IPS were cycled under a simulated AM0 illumination scheme designed to mimic the on-orbit conditions. The IPS will experience a cyclic charging due to the fixed $5^{\circ}$ per second rotation which will result in $24 \mathrm{~s}$ of charge followed by $48 \mathrm{~s}$ of discharge for each $72 \mathrm{~s}$ rotation. In addition, this cycling will occur for 56 minutes and the be followed by 36 minutes of eclipse or continuous discharging due to the 92 minute LEO. ${ }^{6}$ The IPS was tested under a illumination scheme based on the above times using a simulated AM0 source. Examining a single LEO orbit shows the charge discharge behavior due to the rotation of the satellite (see Figure 5).

In addition to the variation in illumination the IPS will also see a thermal variation associated with the LEO orbit. It is anticipated that the IPS will go from $44.0^{\circ} \mathrm{C}$ while in the sun to $-1.0^{\circ}$ $\mathrm{C}$ when in eclipse. Figure 6 shows the voltage on a protoype IPS with a Litestrar battery during 
a simulated LEO orbit with an even more rigorous thermal cycles than anticipated (e.g., plus-orminus $40^{\circ} \mathrm{C}$ ).

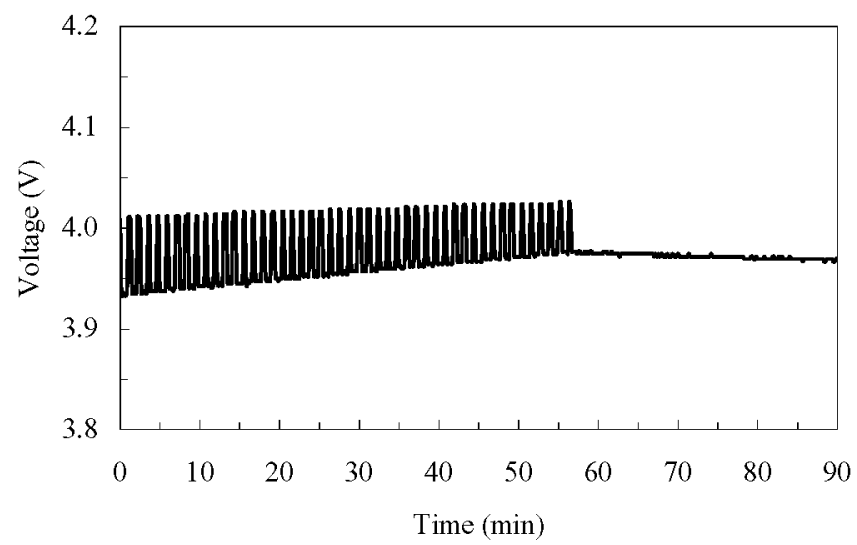

Figure 5. IPS (with Litestar battery) voltage under simulated illumination consistent with a single Starshine 3 orbit (i.e., $5 \% \mathrm{sec}$ rotation and $92 \mathrm{~min}$ LEO orbit).

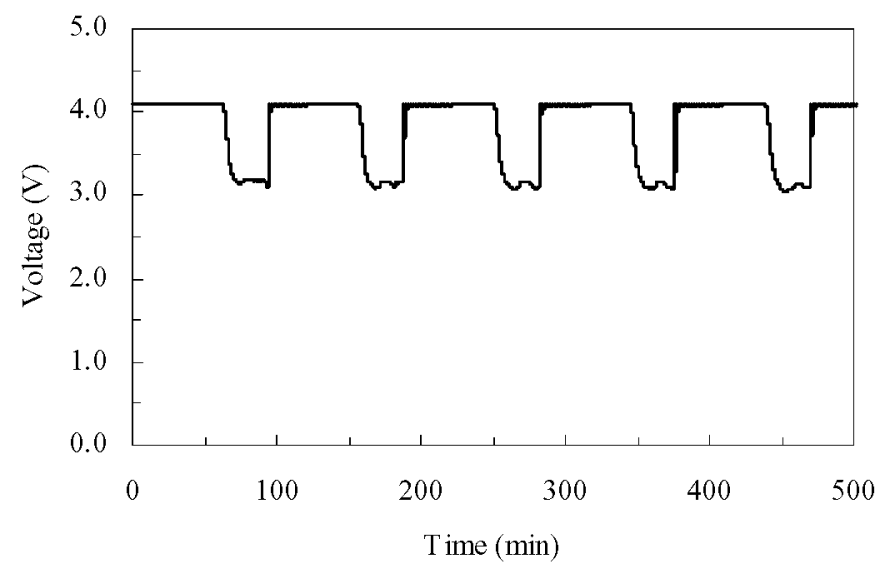

Figure 6. IPS (with Litestar battery) voltage under simulated illumination consistent with a Starshine orbit and thermal fluctuation (i.e., $5^{\circ} / \mathrm{sec}$ rotation, $92 \mathrm{~min}$ LEO orbit, and -40 to $40{ }^{\circ} \mathrm{C}$ temperature variations).

\section{CONCLUSION}

An IPS that combines three traditionally separate power system functions into a single, integrated device is ideal for future small satellites. IPSs should enjoy near-term applicability in specialized instances where they can serve as de-centralized or distributed power sources or uninterruptible power supplies for discrete components. In addition, with future improvement in both thin-film power generation and energy storage they should also find application as a main power system for upcoming missions using constellations of very small spacecraft, or nanosatellites. 


\section{ACKNOWLEDGMENTS}

The authors would like to acknowledge the work performed under NASA Cooperative Agreements NCC3-710 and NCC3-563 with the Rochester Institute of Technology. The authors would also like to thank the Gil Moore and the entire Starshine 3 team, especially our colleagues at the NASA Glenn Research Center.

\section{REFERENCES}

1. P.V. Panetta, H. Culver, J. Gagosian, M. Johnson, J. Kellogg, D. Mangus, T. Michalek, V. Sank, and S. Tompkins, "NASA-GSFC NanoSatellite Technology Development", SSC98-VI5, $12^{\text {th }}$ AIAA/USU Conference on Small Satellites, Logan, UT, August 1998.

2. R.P. Raffaelle, J. Underwood, J.D. Harris, J. Cowen, D. Scheiman, and A.F. Hepp, $28^{\text {th }}$ IEEE Photovolt. Spec. Conference, Anchorage, AK, September 2000.

3. D.J. Hoffman, T.W. Kerslake, A.F. Hepp, M.K. Jacobs, D. Ponnusamy, AIAA-2000-2919, $35^{\text {th }}$ IECEC, Vol.1, pp. 670-680, July 2000 (also NASA/TM-2000-210342).

4. Raffaelle, R.P., Harris, J.D., Hehemann, D., Scheiman, D., Rybicki, G., Hepp, A.F., "A Facile Route to Thin Film Solid State Lithium Microelectronic Batteries", preprint of $J$. of Power Sources 89, 52 (2000).

5. M.A. Green, K. Emery, D.L. King, S. Igari, W. Warta, Prog. In Photovolt. 10, 1 (2002).

6. R. Koksbang, J. Barker, H. Shi, M.Y. Saidi, Solid State Ionics 84, 1 (1996).

7. Lithium Handbook, Pansonic, September 2000.

8. R.P. Raffaelle, J.D. Harris, D. Hehemann, D. Scheiman, G.. Rybicki, A.F. Hepp, IAIAA2000-2808, 35 $5^{\text {th }}$ IECEC, Vol.1, pp. 58-62, July 2000.

9. K. Takada, S. Kondo, Ionics 4, 42 (1998).

10. http://www.azinet.com/starshine/

11. G. Moore, W. Braun, P. Jenkins, W. Holemans, and D. Lefevre, Proceedings of the 15 th Annual/USU Conference on Small Satellites, Logan UT, August 2001.

12. P. Jenkins, D. Scheiman, D. Wilt, R. Raffaelle R. Button, M. Smith, T. Kerslake, and T. Miller, Proceedings of the 15th Annual Small Satellite Conference, AIAA/Utah State University, August 13-16, 2001.

13. C. Clark, J. Summers, J. Armstrong, AIAA-2000-2922, $35^{\text {th }}$ IECEC, Vol.1, pp. 692-698, July 2000 . 